\title{
Severe Delayed Gastric Emptying Induces Non-acid Reflux up to Proximal Esophagus in Neurologically Impaired Patients
}

\author{
Shinji Ishii, ${ }^{1}$ Suguru Fukahori, ${ }^{1 *}$ Kimio Asagiri, ${ }^{1}$ Yoshiaki Tanaka, ${ }^{1,2}$ Nobuyuki Saikusa, ${ }^{1}$ Naoki Hashizume, ${ }^{1}$ Motomu Yoshida, \\ Daisuke Masui, ${ }^{1}$ Naoko Komatsuzaki, ${ }^{1}$ Naruki Higashidate, ${ }^{1}$ Saki Sakamoto, ${ }^{1}$ Tomohiro Kurahachi, ${ }^{1}$ Shiori Tsuruhisa, ${ }^{1}$ Hirotomo \\ Nakahara, ${ }^{1}$ and Minoru Yagi ${ }^{1}$ \\ Departments of ${ }^{l}$ Pediatric Surgery and ${ }^{2}$ Division of Medical Safety Management, Kurume University School of Medicine, Fukuoka, Japan
}

\section{Background/Aims}

The aim of this study is to investigate the degree of delayed gastric emptying (DGE) and evaluate how the severity of DGE affects gastroesophageal reflux disease (GERD) in neurologically impaired (NI) patients utilizing 24-hour multichannel intraluminal impedance $\mathrm{pH}$ measurements (pH/MII) and ${ }^{13} \mathrm{C}$-acetate breath test $\left({ }^{13} \mathrm{C}-\mathrm{ABT}\right)$ analyses.

\section{Methods}

${ }^{13} \mathrm{C}-\mathrm{ABT}$ and $\mathrm{pH} / \mathrm{MII}$ were conducted in $26 \mathrm{NI}$ patients who were referred to our institution due to suspected GERD. At first, correlation analyses were performed to investigate the correlation between the ${ }^{13} \mathrm{C}-\mathrm{ABT}$ parameters and the clinical or $\mathrm{pH} / \mathrm{MIl}$ parameters. Thereafter, all patients were divided into 2 groups (DGE and severe DGE [SDGE] group) according to each cut off half emptying time ( $t_{1 / 2}, 90-170$ minutes). Each pH/MII parameter was compared between the 2 groups in each set-up cutoff $t_{1 / 2}$.

\section{Results}

The mean $t_{1 / 2}$ of all patients was $215.5 \pm 237.2$ minutes and the $t_{1 / 2}$ of $24(92.3 \%)$ patients were $>100$ minutes. Significant moderate positive correlations were observed between both $t_{1 / 2}$ and lag phase time and the non-acid reflux related parameters. Furthermore, the patients in the SDGE group demonstrated higher non-acid reflux related parameters than those of the DGE groups when the cutoff was $t_{1 / 2} \geq 140$ minutes.

\section{Conclusion}

The present study demonstrated that GE with $t_{1 / 2} \geq 140$ minutes was related to an increase of non-acid exposure reaching up to the proximal esophagus in NI patients, and indicating that NI patients with SDGE might have a high risk of non-acid GERD.

(J Neurogastroenterol Motil 2017;23:533-540)

Key Words

Breath test; Disabled patient; Gastric emptying; Gastroesophageal reflux; Multichannel intraluminal impedance measurements

Received: December 13, 2016 Revised: March 4, 2017 Accepted: April 2, 2017

(a) This is an Open Access article distributed under the terms of the Creative Commons Attribution Non-Commercial License (http://creativecommons. org/licenses/by-nc/4.0) which permits unrestricted non-commercial use, distribution, and reproduction in any medium, provided the original work is properly cited.

${ }^{*}$ Correspondence: Suguru Fukahori, MD, PhD

Department of Pediatric Surgery, Kurume University School of Medicine, 67 Asahi-machi, Kurume, Fukuoka 830-0011, Japan Tel: +81-942-31-7631, Fax: +81-942-31-7705, E-mail: s_fukahori@med.kurume-u.ac.jp 


\section{Introduction}

Gastroesophageal reflux disease (GERD) has been one of the most critical conditions for neurologically impaired (NI) patients with a high incidence. ${ }^{1,2}$

Although the relationship between delayed gastric emptying (DGE) and GERD is still controversial, with some authors reporting a significant association between the 2 conditions ${ }^{3,4}$ and others reporting no correlation, ${ }^{5,6}$ several authors have described that the presence of DGE increases the probability and rate of gastroesophageal reflux (GER) episodes. ${ }^{7-10}$ DGE has also been documented with an increasing frequency in infants and children with symptoms of GERD. In particular, DGE is common in patients with esophageal atresia or $\mathrm{NI}^{11-14}$ at an incidence of $>50.0 \%$. As an empirically acceptable pathophysiology, it has been suggested that DGE could be an important contributor to GER by increasing esophageal exposure in the postprandial period, ${ }^{3,4}$ indicating the accentuation of postprandial reflux is likely due to an increased volume of refluxate per episode of reflux through an underlying incompetent lower esophageal sphincter (LES). ${ }^{3}$ A reduction in meal size or adding pyloroplasty to fundoplication with the aim of reducing the postoperative complications and recurrence of $\mathrm{GERD}^{10,15,16}$ have been used in clinical practice as therapeutic options for GERD accompanying DGE.

As mentioned above, it is well recognized that DGE contributes to the aggravation of GERD in NI patients. However, most reports have only referred to the relationship between acid GERD and DGE according to $\mathrm{pH}$ monitoring, which only examines acid GERD. Indeed, a previous report evaluated by $\mathrm{pH}$ monitoring indicated that although a large proportion of NI patients manifest moderate to severe GERD and its complications, they do not have DGE. ${ }^{5}$ Moreover, it remains unclear how the severity of DGE affects the aggravation of GERD.

Twenty-four hour multichannel, intraluminal impedance $\mathrm{pH}$ measurements ( $\mathrm{pH} / \mathrm{MII})$ have recently emerged as a novel technique to evaluate GERD irrespective of the $\mathrm{pH}$ value. As $\mathrm{pH} / \mathrm{MII}$ has recently been introduced for clinical use, non-acid GERD has received attention and a close relationship between non-acid GERD and NI has been suggested. Additionally, a previous study reported that more than half of the reflux events in NI children were nonacidic detected by $\mathrm{pH} / \mathrm{MII} .^{17}$

Although the presence of non-acid reflux is potentially related to DGE in NI patients, to the best of our knowledge, only one report thus far has investigated the relationship between non-acid reflux and DGE in NI patients. ${ }^{18}$ Thus, the detailed pathophysiology of DGE in NI patients with GERD including non-acid reflux remains controversial.

The aim of this study is to investigate the degree of GE in NI patients and to evaluate how the severity of DGE affects GERD, including both acid and non-acid reflux, in NI patients by utilizing both 24-hour $\mathrm{pH} / \mathrm{MII}$ and ${ }^{13} \mathrm{C}$-acetate breath test $\left({ }^{13} \mathrm{C}\right.$-ABT $)$ analyses.

\section{Materials and Methods}

This retrospective study included NI patients, who underwent gastrointestinal examinations between 2011 and 2014 at the Kurume University hospital. Medications for GERD were stopped at least 3 days before entering the study, and upper gastrointestinal endoscopy and barium swallowing were performed in all casesthere were no abnormal findings that affected gastric emptying. All enrolled NI patients were evaluated using both GE measurements and 24-hour $\mathrm{pH} / \mathrm{MII}$. The study protocol was approved by the Kurume University Ethical Committee (No. 2575 and 11049). Informed consent was obtained from their families before their enrollment in this study.

$\mathrm{GE}$ was evaluated using the ${ }^{13} \mathrm{C}$-ABT (the Breath ID system; Oridion Breath ID Ltd, Jerusalem, Israel) after the ingestion of a liquid meal (Racol; Otsuka Pharmaceutical Co, Ltd, Tokyo, Japan), which is a semi-digested (osmotic pressure: 330-360 mOsm/ L) as a test meal. The nutrient compositions of $100 \mathrm{~mL}$ of the liquid meal $(100 \mathrm{kcal} / \mathrm{mL})$ were $4.4 \mathrm{~g}$ of protein extracted from casein and soybean, $15.6 \mathrm{~g}$ of carbohydrate, and $2.2 \mathrm{~g}$ of fat. The test meal was administered via a nasogastric tube in 24 patients, and via gastrostomy in 2 patient within 5 minutes. The breath test was performed by accumulating each subject's exhaled gas via a nasal cannula for breath testing. After a baseline collection of the patient's breath, all patients were administered $10 \mathrm{~mL} / \mathrm{kg}$ (maximum dose $100 \mathrm{~mL}$ ) of the test meal, in which $100 \mathrm{mg}$ of ${ }^{13} \mathrm{C}$-labeled sodium acetate was dissolved, and were tested in the semi-Fowler's position after more than 6 hours of fasting. The test meal was processed and emptied by the stomach. After absorption and metabolism, ${ }^{13} \mathrm{C}$ was derived and exhaled in the breath as $\mathrm{CO}_{2}$. The device continuously measures the ratio of ${ }^{13} \mathrm{C}$ and ${ }^{12} \mathrm{C}$ in the $\mathrm{CO}_{2}$ of the exhaled breath for 4 hours using molecular correlation spectroscopy. The Breath ID device measures the ratio and the ${ }^{13} \mathrm{C}$ substrate and dose, and provides the percentage dose recovery and cumulative percentage dose recovery. It then calculates the half emptying time ( $t_{1 / 2}$, minute), the lag phase time $\left(t_{\text {lag }}\right)$, and the gastric emptying coefficient 
(GEC), based on a non-linear analysis as described by Ghoos et al. ${ }^{19} \mathrm{GE}$ was expressed as $\mathrm{t}_{1 / 2} \cdot \mathrm{t}_{\mathrm{lag}}$ and GEC was also evaluated as automatically analyzed parameters. $t_{1 / 2}$ is the time required for half of the gastric contents to be emptied. $t_{\text {lag }}$ is the time at the point of inflection of the curve after mathematical integration, and GEC is an index of the global gastric emptying rate. A shorter $t_{1 / 2}$ and $t_{\text {lag }}$ and a higher GEC suggest accelerated gastric emptying.

In the analysis of 24-hour pH/MII, a multiple intraluminal impedance catheter (outer diameter, $2 \mathrm{~mm}$ ) with $2 \mathrm{pH}$ antimony electrodes and 7 impedance electrodes (Sandhill Scientific, Inc, Highlands Ranch, CO, USA) was used. This technique can assess the esophageal flow by measuring changes in conductivity (impedance value) of the esophageal content between multiple electrode pairs on a catheter. The main advantage of this device is its ability to detect not only acid, but also non-acid reflux episodes and the height of refluxate. The catheter was inserted transnasally through the esophagus, and $\mathrm{pH}$ sensor placement was confirmed by radiography. Obtained data from the 24-hour $\mathrm{pH} / \mathrm{MII}$ was automatically evaluated using the BioVIEW analysis software program (Sandhill Scientific, Inc, Highlands Ranch, CO, USA) and each tracing was manually reviewed by the same investigators (S.I. and S.F.). Liquid reflux was defined as a fall in impedance more than or equal to $50.0 \%$ from the baseline occurring in at least 2 consecutive channels in an abnormal direction. Each type of reflux was defined as follows: acid reflux, associated $\mathrm{pH}$ drop to $\leq 4$, and non-acid reflux, associated $\mathrm{pH}$ value above 4 . The $\mathrm{pH}$ index was defined as the percentage of time with a $\mathrm{pH}$ value $\leq 4$. A high cut-off value was defined as $4.0 \%$ according to the definition of the Working Group of Japanese Society for Pediatric Alimentary Motility. ${ }^{20}$ The bolus exposure index (BEI) was defined as the percentage of time with retrograde movement of intraluminal esophageal material. A high cut-off value was defined as $1.4 \%$ (higher than the 95th percentile of normal 24-hour pH/MII values, as suggested by Shay et $\mathrm{al}^{21}$ in an adult series of healthy patients). Pathological GERD was defined as a $\mathrm{pH}$ index $>4.0 \%$ or a $\mathrm{BEI}>1.4 \%$.

At first, correlation analyses were performed to investigate the correlation between the ${ }^{13} \mathrm{C}$-ABT parameters $\left(t_{1 / 2}, t_{\text {lag }}\right.$, and GEC) and the clinical parameters (age, gender, height, body weight, causal disorders of NI [congenital or acquired], and the degree of scoliosis) or the $\mathrm{pH} / \mathrm{MII}$ parameters (BEI [total, acid, and non-acid], and the number of reflux and proximal reflux episodes [total, acid, and non-acid]), respectively.

Thereafter, all patients were divided into 2 groups (the DGE group and the severe DGE [SDGE] group) according to each setup cut off $\mathrm{t}_{1 / 2}(90,100,110,120,130,140,150,160$, and $170 \mathrm{~min}-$ utes). Each of the $\mathrm{pH} / \mathrm{MII}$ parameters were compared between the 2 groups in each set-up cutoff $\mathrm{t}_{1 / 2}$.

All statistical analyses were performed with the JMP Pro 11 software program (SAS Institute Inc, Cary, NC, USA). The numerical data were expressed as the mean \pm standard deviation and range. A Spearman's correlation analysis was used to investigate the correlation between the ${ }^{13} \mathrm{C}-\mathrm{ABT}$ and the clinical or $\mathrm{pH} / \mathrm{MII}$ parameters. The Mann-Whitney $U$ test was used for nonparametric analyses. $P$-values less than 0.05 were considered to be statistically significant.

\section{Results}

Twenty-six NI patients were enrolled in this study (male/female, 12/14; mean age, $17.11 \pm 15.59$ years [range, 11 months-41 years]; mean height, $1.16 \pm 0.32$ [range, 0.70-1.58] $\mathrm{m}$; mean body weight, $20.47 \pm 12.21$ [range, 5.00-44.00] kg; mean body mass index, $13.86 \pm 3.06$ [range, 8.61-20.09] kg/m²). All patients had profound NI due to a congenital disorder (cerebral palsy $[\mathrm{n}=$ $15]$, chromosomal anomaly $[\mathrm{n}=5]$ ) or acquired disorder (hypoxic brain damage $[\mathrm{n}=6])$, and were referred to our institution due to symptoms of suspected GERD. Feeding was achieved orally ( $\mathrm{n}=$ 1) or enterally $(n=25)$ (nutrients were continuously administered for more than an hour, 3 to 5 times a day), via a nasogastric tube (n $=23$ ) and via a gastrostomy $(\mathrm{n}=2)$. The mean Cobb angle of all NI patients was $38.89 \pm 34.81$ degrees.

Based on the GERD examination by 24-hour pH/MII analyses, 14 patients were diagnosed with pathological GERD (53.8\%), and 12 were diagnosed with non-pathological GERD (46.2\%). The above data for the clinical parameters and details results of $\mathrm{pH} /$ MII parameters in all NI patients are shown in Tables 1 and 2, respectively.

In the GE measurements by ${ }^{13} \mathrm{C}-\mathrm{ABT}$ in all NI patients, the mean $t_{1 / 2}, t_{l a g}$, and GEC for all NI patients were $215.5 \pm 237.2$ (range, 105.4-1061.6) minutes, $81.7 \pm 67.9$ (range, 26.2-316.9) minutes, and $3.2 \pm 0.6$ (range, 2.0-3.9), respectively. The $t_{1 / 2}$ of 24 $(92.3 \%)$ patients was over 100 minutes (Figure).

The correlation analyses between the ${ }^{13} \mathrm{C}-\mathrm{ABT}$ and clinical parameters revealed no significant correlations between the ${ }^{13} \mathrm{C}-\mathrm{ABT}$ parameters and the clinical parameters (Table 1). The correlation analyses between the ${ }^{13} \mathrm{C}$-ABT parameters and the $\mathrm{pH} / \mathrm{MII}$ parameters revealed significant moderate positive correlations between both $t_{1 / 2}$ and $t_{\operatorname{lag}}$ and the non-acid related parameters (BEI [non-acid] and the numbers of total and non-acid reflux and total and nonacid proximal reflux episodes). In contrast, no significant correlation 
Table 1. The Correlation Analyses Between the Clinical and ${ }^{13} \mathrm{C}$-acetate Breath Test Parameters

\begin{tabular}{lcccc}
\hline \multicolumn{1}{c}{ Clinical parameters } & No. or mean $\pm \mathrm{SD}$ & $\mathrm{t}_{\text {lag }}(P$-value $)$ & $\mathrm{t}_{1 / 2}(P$-value $)$ & GEC $(P$-value $)$ \\
\hline Age (yr) & $17.11 \pm 15.59$ & 0.609 & 0.583 & 0.489 \\
Gender (M/F) & $12 / 14$ & 0.939 & 0.738 & 0.980 \\
Height (m) & $1.16 \pm 0.32$ & 0.822 & 0.599 & 0.294 \\
Body weight (kg) & $20.47 \pm 12.21$ & 0.270 & 0.164 & 0.630 \\
Causal disorder (C/A) & $20 / 6$ & 0.879 & 0.692 & 0.605 \\
Scoliosis (Cobb angle, degree) & $38.89 \pm 34.81$ & 0.370 & 0.176 & 0.500 \\
Pathological GERD (+/-) & $14 / 12$ & 0.625 & 0.625 & 0.898 \\
\hline
\end{tabular}

$\mathrm{t}_{\text {lag }}$, lag phase time; $\mathrm{t}_{1 / 2}$, half-emptying time; GEC, gastric emptying coefficient; M/F, male/female; C/A, congenital (cerebral palsy and chromosomal anomaly)/acquired (hypoxic brain damage); GERD, gastroesophageal reflux disease.

Table 2. The Correlation Analyses Between ${ }^{13} \mathrm{C}$-acetate Breath Test and Multichannel Intraluminal Impedance pH Measurement Parameters

\begin{tabular}{|c|c|c|c|c|c|c|c|c|}
\hline \multirow{2}{*}{ Parameters } & \multirow{2}{*}{$\begin{array}{c}\text { Mean } \\
\text { Mean } \pm \mathrm{SD}\end{array}$} & \multirow{2}{*}{$\frac{\text { Median }}{\text { Median (range) }}$} & \multicolumn{2}{|c|}{$\mathrm{t}_{\mathrm{lag}}$} & \multicolumn{2}{|c|}{$\mathrm{t}_{1 / 2}$} & \multicolumn{2}{|c|}{ GEC } \\
\hline & & & $r$ & $P$-value & $R$ & $P$-value & $r$ & $P$-value \\
\hline $\mathrm{pHI}(\%)$ & $6.07 \pm 8.94$ & $2.15(0.0-39.1)$ & -0.076 & 0.714 & -0.043 & 0.836 & 0.322 & 0.109 \\
\hline BEI (total, \%) & $2.21 \pm 4.03$ & $1.1(0.1-20.4)$ & 0.226 & 0.267 & 0.216 & 0.289 & -0.020 & 0.925 \\
\hline BEI (acid, \%) & $1.58 \pm 3.87$ & $0.65(0.0-20.2)$ & 0.060 & 0.772 & 0.035 & 0.865 & 0.082 & 0.691 \\
\hline BEI (non-acid, \%) & $0.62 \pm 1.24$ & $0.25(0.0-6.4)$ & 0.412 & $0.036^{\mathrm{a}}$ & 0.450 & $0.021^{\mathrm{a}}$ & -0.264 & 0.193 \\
\hline REs (total, n) & $43 \pm 22$ & $45(1-80)$ & 0.466 & $0.016^{\mathrm{a}}$ & 0.445 & $0.023^{\mathrm{a}}$ & -0.310 & 0.124 \\
\hline REs (acid, n) & $26 \pm 18$ & $25(0-69)$ & 0.221 & 0.278 & 0.181 & 0.375 & -0.071 & 0.730 \\
\hline REs (non-acid, n) & $17 \pm 13$ & $13(1-59)$ & 0.463 & $0.017^{\mathrm{a}}$ & 0.466 & $0.016^{\mathrm{a}}$ & 0.305 & 0.130 \\
\hline PREs (total, n) & $15.27 \pm 15.05$ & $13.5(0-76)$ & 0.315 & 0.117 & 0.403 & $0.041^{\mathrm{a}}$ & -0.237 & 0.244 \\
\hline PREs (acid, n) & $9.58 \pm 9.33$ & $7(0-42)$ & 0.177 & 0.387 & 0.228 & 0.263 & -0.013 & 0.949 \\
\hline PREs (non-acid, n) & $5.69 \pm 7.52$ & $3(0-34)$ & 0.324 & 0.106 & 0.429 & $0.029^{\mathrm{a}}$ & -0.315 & 0.117 \\
\hline
\end{tabular}

${ }^{\mathrm{a}} \mathrm{P}<0.05$.

$t_{\text {lag }}$, lag phase time; $t_{1 / 2}$, half emptying time; GEC, gastric emptying coefficient; pHI, pH index; BEI, bolus exposure index; REs, reflux episodes; PREs, proximal reflux episodes.
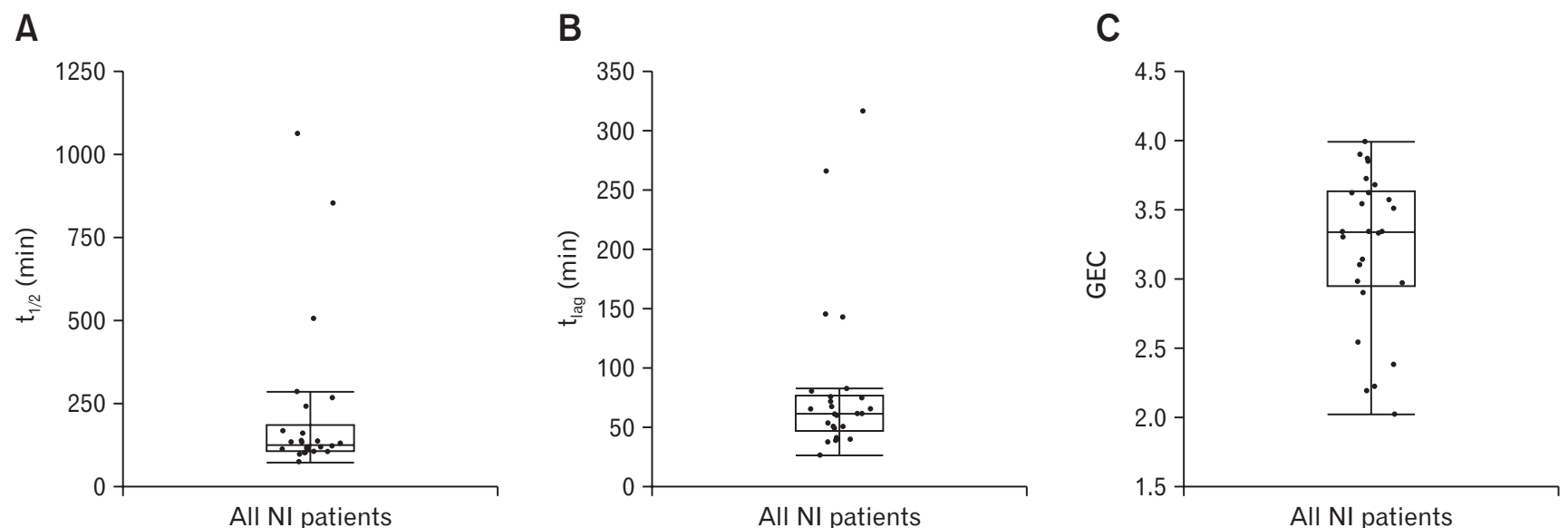

Figure. In the gastric emptying measurements by ${ }^{13} \mathrm{C}$-acetate breath test $\left({ }^{13} \mathrm{C}\right.$-ABT) in all neurologically impaired (NI) patients, the mean half emptying time $\left(t_{1 / 2}\right)$, lag phase time $\left(t_{\text {lag }}\right)$, and gastric emptying coefficient (GEC) for all NI patients were 215.5 \pm 237.2 (range, 105.4-1061.6) minutes (A), $81.7 \pm 67.9$ (range, 26.2-316.9) minutes (B), and $3.2 \pm 0.6$ (range, 2.0-3.9) (C), respectively. The $t_{1 / 2}$ of 24 (92.3\%) patients was over 100 minutes. 
was observed between the acid-related parameters ( $\mathrm{pH}$ index, BEI [total/acid], and the number of acid reflux and acid proximal reflux episodes) and any ${ }^{13} \mathrm{C}$-ABT parameters. GEC showed no significant correlations with any $\mathrm{pH} / \mathrm{MII}$ parameters (Table 2).

The detailed $\mathrm{pH} / \mathrm{MII}$ parameters of the patients classified into the DGE and SDGE groups according to each cutoff $\mathrm{t}_{1 / 2}$ are shown in Table 3.

In the comparison of the $\mathrm{pH} / \mathrm{MII}$ parameters between the DGE and SDGE groups at each set-up cutoff $t_{1 / 2}$ value, a significant difference in the BEI (non-acid) values and the number of total reflux episodes was observed between the DGE and SDGE groups when the cutoff $t_{1 / 2}$ was set to $\geq 130$ minutes. Furthermore, when it was set to $\geq 140$ minutes, there were significant differences between the 2 groups in the numbers of non-acid reflux episodes and the numbers of proximal total and non-acid reflux episodes (Table 3).

\section{Discussion}

The present study investigated gastric emptying using the ${ }^{13} \mathrm{C}$ $\mathrm{ABT}$ and the liquid test meal because most NI patients receive enteral feeding via a nasogastric tube or gastrostomy. Several reports thus far have evaluated the normal value of $\mathrm{t}_{1 / 2}$ in neurologically normal subjects analyzed by technetium- $99 \mathrm{~m}$ scintigraphy or ${ }^{13} \mathrm{C}$ octanoic acid breath test analysis. ${ }^{5,19,22-24}$ Regarding the normal range of gastric emptying analyzed by the ${ }^{13} \mathrm{C}-\mathrm{ABT}$, Gatti et al ${ }^{22}$ reported that the mean $\mathrm{t}_{1 / 2}$ with milk as the test meal was $74 \pm 12$ minutes in healthy children. Hauser et $\mathrm{al}^{25}$ reported that the median $t_{1 / 2}$ value in 21 healthy children was 81 (65-112) minutes. These previous reports set a longer threshold of $t_{1 / 2}$ at 90 minutes. Additionally, several reports have attempted to investigate GE of NI patients, although no report has demonstrated the normal range in NI patients. Kawahara et $\mathrm{a}^{12,13}$ examined GE of $30 \mathrm{NI}$ patients and their $\mathrm{t}_{1 / 2}$ ranged from 75-204 minutes; 16 (53.0\%) patients had a $\mathrm{t}_{1 / 2}$ longer than 100 minutes. Okada et al ${ }^{26}$ examined 5 NI patients and their mean $\mathrm{t}_{1 / 2}$ was 1.8 hours.

In the present study, the mean $t_{1 / 2}$ of all patients was 215.5 minutes and the $t_{1 / 2}$ of 24 (92.3\%) patients were over 100 minutes. These results appear to be longer than those that previously reported. The mechanisms of DGE in NI patients, similar to GERD, might be considered as the cause of aggravated gastric emptying via affected gastric motility, such as abnormal modulation of extrinsic innervations due to a damaged central nervous system or hypoxicischemic damage to the enteric nerves. ${ }^{27}$ Moreover, a combination of several factors, such as scoliosis, horizontal position and long-

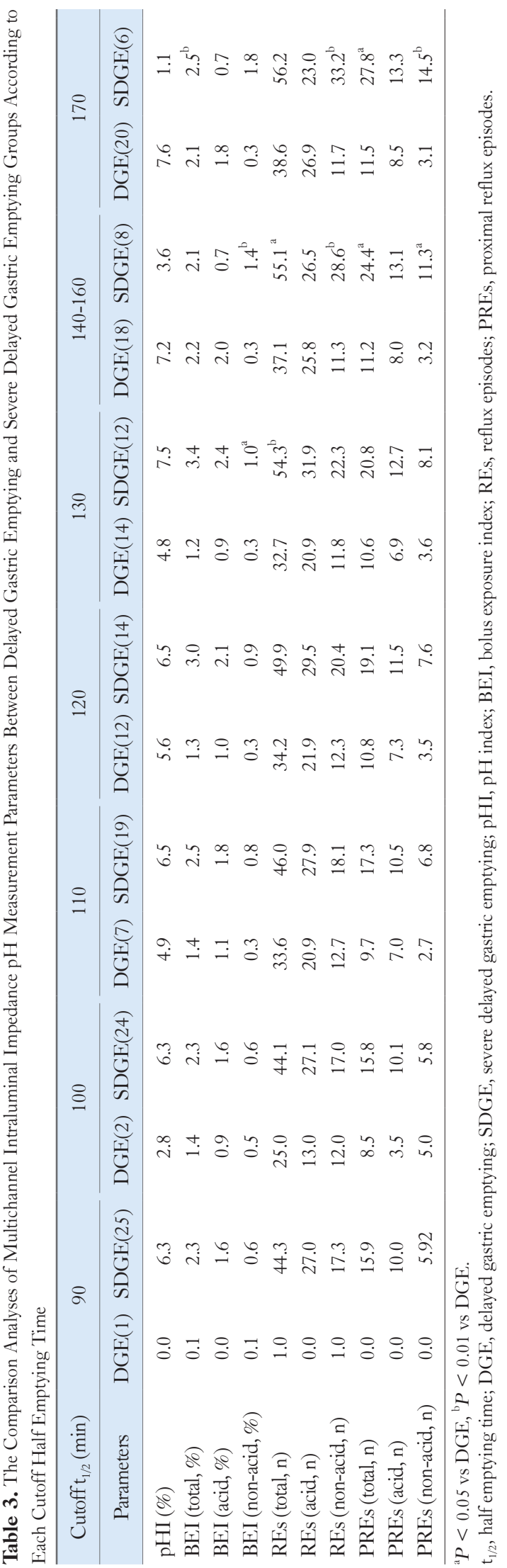


term anticonvulsant use potentially delays GE. Gatti et $\mathrm{al}^{22}$ also indicated that severe $\mathrm{NI}$ in children is associated with a high probability of DGE. We speculated that the patients enrolled in the present study were complicated by more of the above-mentioned factors that affect GE than the patients in previous studies.

The relationship between the clinical parameters, such as causal disorders and scoliosis and the $t_{1 / 2}$ and $t_{\operatorname{lag}}$ values in NI patients was evaluated. However, no significant difference was observed. As a consequence, the present study could not detect the cause of SDGE according to the clinical parameters. Furthermore, no significant difference was observed in any ${ }^{13} \mathrm{C}$-ABT parameters between GERD (+) and GERD (-), findings which were the opposite of what was expected. We suspect that other factors, such as the proximal gastric accommodation, reported to be closely related to an increase in the transient LES relaxation, ${ }^{28}$ which is known as the main mechanism of GERD, might have affected the present results. GEC is an index, equivalent to the slope in the early phase of the velocity curve of GE, and a higher GEC suggests an accelerated GE. Previous studies also measured the GEC, but did not mention its significance. In the present study, GEC did not demonstrate a significant relationship with any parameters, so we were unable to clarify its meaning.

Following the introduction of $\mathrm{pH} / \mathrm{MII}$ in clinical practice, studies evaluating non-acid reflux have increased, gradually clarifying its pathophysiology. Regarding the relationship between nonacid reflux and NI, Del Buono et $\mathrm{al}^{17}$ reported that more than half of the reflux events in NI children were non-acid; we also indicated that NI patients fed via a nasogastric tube suffered more non-acid reflux episodes than those fed orally. ${ }^{29}$

Few reports thus far have analyzed the relationship between gastric emptying and non-acid GERD using $\mathrm{pH} / \mathrm{MII}$, although a close relationship between DGE and GERD in both adults and children has been reported from a considerable number of studies. Emerenziani et $\mathrm{al}^{30}$ reported a significant relationship between reflux acidity and gastric emptying; namely, the slower the emptying, the higher the $\mathrm{pH}$ of the refluxate. To the best of our knowledge, Kawahara et $\mathrm{al}^{12,13}$ are the only investigators who reported the relationship between DGE and GERD in NI patients by utilizing both $\mathrm{pH} / \mathrm{MII}$ and ${ }^{13} \mathrm{C}-\mathrm{ABT}$ analyses; they concluded that there was no significant relationships between DGE and GERD.

The primary findings in the present study were that significant moderate correlations were observed between all of the nonacid related parameters and the $t_{1 / 2}$ or $t_{\text {ag }}$ values. Moreover, in the comparison analyses of the $\mathrm{pH} / \mathrm{MII}$ parameters and the cutoff values of $t_{1 / 2}$ in the DGE and SDGE groups, significant increases were observed in the non-acid related parameters of the patients of the SDGE group when the cut off $t_{1 / 2}$ was set to $\geq 140$ minutes. These findings indicate that $t_{1 / 2} \geq 140$ minutes potentially increases the exposure of non-acid reflux in the distal as well as the proximal esophagus in NI patients. Our oppositional findings from that of Kawahara et $\mathrm{al}^{12,13}$ might be due to the high proportion of DGE in the present study. It has been suggested that long-term retained enteral feeding buffers gastric juice; when the gastric pressure is higher than the LES, such as in the condition of seizures or the presence of transient LES relaxations, then the buffered gastric content flows into the esophagus. Schwizer et $\mathrm{al}^{31}$ reported that the severity of GERD in patients with DGE was lower than that in patients without DGE, indicating that buffering of the gastric juice due to the presence of DGE changes acid reflux to weakly-acid reflux, which reduces damage to the esophageal mucosa.

Rebound acid hypersecretion after the discontinuation of proton pump inhibitor has been reported to be a factor affecting the $\mathrm{pH} .{ }^{32}$ In the present study, four patients received proton pump inhibitors before stopping the medication, while 21 did not. No significant difference was observed between these 2 groups with regard to the percentage of time for which the gastric $\mathrm{pH}$ was $<4$ $(P=0.972)$.

A previous study described a close relationship between nonacid reflux reaching the proximal esophagus and aspiration in children. ${ }^{33}$ This suggests that a certain percentage of NI patients are likely at risk of aspiration due to non-acid reflux.

Based on the present results, improving the SDGE detected by ${ }^{13} \mathrm{C}$-ABT might reduce the risk of aspiration due to non-acid GER reaching the proximal esophagus in NI patients requiring enteral feeding. Therefore, as these patients cannot complain their symptoms, the administration of prokinetic drugs with enteral feeding may be beneficial, although ideally, gastric emptying of all NI patients should be evaluated by ${ }^{13} \mathrm{C}-\mathrm{ABT}$, regardless of symptoms.

In summary, a considerably high proportion of NI patients demonstrated DGE with $\mathrm{t}_{1 / 2}$ above 100 minutes, and the patients with $t_{1 / 2} \geq 140$ minutes suffered more non-acid exposure reaching up to the proximal esophagus, whereas no obvious clinical causes of SDGE were detected in the present study. Generally, NI patients tended to show a higher frequency of DGE in comparison to healthy individuals. As a result, it remains debatable whether a comparison of gastric emptying between NI patients and neurologically normal patients is appropriate. Considering that most NI patients spend the majority of their lives under abnormal circumstances, such as feeding via a nasogastric tube in the supine position compared to neurologically normal patients, the normal range of gastric 
emptying in NI patients might be defined separately from that of neurologically healthy subjects.

There are several limitations associated with the present study. First, the age of the enrolled patients ranged from children to adults because gastric emptying of children has been reported to be the same as that of adults. ${ }^{19,22-24}$ Therefore, we did not take age distribution into consideration. However, the possibility that the age difference affected the gastric emptying cannot be ruled out. Second, the dosage of the test meal was calculated according to the body weight of each patient because in NI patient, it might be difficult to determine the optimal dose due to the presence of growth failure and wasting, compared to neurologically normal subjects of the same age. However, several reports have determined the optimal dose according to the body surface area ${ }^{11,12}$ or recommended as a dose of $200 \mathrm{~mL}$ for adults. Such limitations in the present study might have affected the results.

In conclusion, the present study demonstrated that GE with $t_{1 / 2} \geq 140$ minutes was related to an increase of non-acid exposure reaching up to the proximal esophagus in NI patients, indicating that NI patients with SDGE might have a risk of non-acid GERD. Further studies enrolling a large number of subjects are required to elucidate the precise pathophysiological mechanism involved in the relationship between non-acid GERD and SDGE in NI patients.

\section{Financial support: None.}

\section{Conflicts of interest: None}

Author contributions: Shinji Ishii performed the experiments and data analysis, and prepared the manuscript; Suguru Fukahori, Kimio Asagiri, and Yoshiaki Tanaka supervised the planning and execution of the experiments and statistical analysis, and reviewed the manuscript; Nobuyuki Saikusa assisted with conducting some of the experiments; Naoki Hashizume, Motomu Yoshida, Daisuke Masui, Naoko Komatsuzaki, Naruki Higashidate, Saki Sakamoto, Tomohiro Kurahachi, Shiori Tsuruhisa, and Hirotomo Nakahara assisted with the execution of the experiments and reviewed the manuscript; and Minoru Yagi supervised the planning and execution of the experiments, and reviewed the manuscript.

\section{References}

1. Boix-Ochoa J, Rowe MI. Gastroesophageal reflux. Pediatric Surgery 1998;66:1007-1028.

2. Ceriati E, De Peppo F, Ciprandi G, Marchetti P, Silveri M, Rivosecchi
M. Surgery in disabled children: general gastroenterological aspects. Acta Paediatr 2006;95(suppl 452):34-37.

3. Estevão-Costa J, Campos M, Dias JA, Trindade E, Medina AM, Carvalho JL. Delayed gastric emptying and gastroesophageal reflux: a pathophysiologic relationship. J Pediatr Gastroenterol Nutr 2001;32:471474.

4. Argon M, Duygun U, Daglioz G, Omür O, Demir E, Aydogdu S. Relationship between gastric emptying and gastroesophageal reflux in infants and children. Clin Nucl Med 2006;31:262-265.

5. Spiroglou K, Xinias I, Karatzas N, Karatza E, Arsos G, Panteliadis C. Gastric emptying in children with cerebral palsy and gastroesophageal reflux. Pediatr Neurol 2004;31:177-182.

6. Machado RS, Yamamoto E, da Silva Patrício FR, Reber M, Kawakami E. Gastric emptying evaluation in children with erosive gastroesophageal reflux disease. Pediatr Surg Int 2010;26:473-478.

7. Benini L, Sembenini C, Castellani G, Caliari S, Fioretta A, Vantini I. Gastric emptying and dyspeptic symptoms in patients with gastroesophageal reflux. Am J Gastroenterol 1996;91:1351-1354.

8. Cunningham KM, Horowitz M, Riddell PS ,et al. Relations among autonomic nerve dysfunction, oesophageal motility, and gastric emptying in gastro-oesophageal reflux disease. Gut 1991;32:1436-1440.

9. McCallum RW, Berkowitz DM, Lerner E. Gastric emptying in patients with gastroesophageal reflux. Gastroenterology 1981;80:285-291.

10. Richter JE. Delayed gastric emptying in reflux patients: to be or not to be? Am J Gastroenterol 1997;92:1077-1078.

11. Alexander F, Wyllie R, Jirousek K, Secic M, Porvasnik S. Delayed gastric emptying affects outcome of Nissen fundoplication in neurologically impaired children. Surgery 1997;122:690-697; discussion 697-698.

12. Kawahara H, Mitani Y, Nomura M, et al. Impact of rikkunshito, an herbal medicine, on delayed gastric emptying in profoundly handicapped patients. Pediatr Surg Int 2009;25:987-990.

13. Kawahara H, Tazuke Y, Soh H, Yoneda A, Fukuzawa M. Does laparoscopy-aided gastrostomy placement improve or worsen gastroesophageal reflux in patients with neurological impairment? J Pediatr Surg 2014;49:1742-1745

14. Fonkalsrud EW, Ament ME. Gastroesophageal reflux in childhood. Curr Probl Surg 1996;33:1-70.

15. Bustorff-Silva J, Fonkalsrud EW, Perez CA, et al. Gastric emptying procedures decrease the risk of postoperative recurrent reflux in children with delayed gastric emptying. J Pediatr Surg 1999;34:79-82; discussion 82-83

16. Fonkalsrud EW, Foglia RP, Ament ME, Berquist W, Vargas J. Operative treatment for the gastroesophageal reflux syndrome in children. J Pediatr Surg 1989;24:525-529.

17. Del Buono R, Wenzl TG, Rawat D, Thomson M. Acid and nonacid gastro-oesophageal reflux in neurologically impaired children: investigation with the multiple intraluminal impedance procedure. J Pediatr Gastroenterol Nutr 2006;43:331-335.

18. Kawahara H, Tazuke Y, Soh H, Usui N, Fukuzawa M. Causal relationship between delayed gastric emptying and gastroesophageal reflux in patients with neurological impairment. Pediatr Surg Int 2015;31:917-923.

19. Ghoos YF, Maes BD, Geypens BJ, et al. Measurement of gastric empty- 
ing rate of solids by means of a carbon-labeled octanoic acid breath test. Gastroenterology 1993;104:1640-1647.

20. Ohhama Y, Suzuki N. [Working Group of Japanese Society for Pediatric Alimentary Motility: guidelines for pediatric 24-h esophageal $\mathrm{pH}$ monitoring.] Jpn J Pediatr Surg 1997;29:1255-1263. [Japanese]

21. Shay S, Tutuian R, Sifrim D, et al. Twenty-four hour ambulatory simultaneous impedance and $\mathrm{pH}$ monitoring: a multicenter report of normal values from 60 healthy volunteers. Am J Gastroenterol 2004;99:10371043.

22. Gatti C, di Abriola FF, Dall'Oglio L, Villa M, Franchini F, Amarri S. Is the ${ }^{13} \mathrm{C}$-acetate breath test a valid procedure to analyse gastric emptying in children? J Pediatr Surg 2000;35:62-65.

23. Braden B, Adams S, Duan LP, et al. The $\left[{ }^{13} \mathrm{C}\right]$ acetate breath test accurately reflects gastric emptying of liquids in both liquid and semisolid test meals. Gastroenterology 1995;108:1048-1055.

24. Lysy J, Israeli E, Strauss-Liviatan N, Goldin E. Relationships between hypoglycaemia and gastric emptying abnormalities in insulin-treated diabetic patients. Neurogastroenterol Motil 2006;18:433-440.

25. Hauser B, De Schepper J, Caveliers V, et al. Variability of the ${ }^{13} \mathrm{C}$-acetate breath test for gastric emptying of liquids in healthy children. J Pediatr Gastroenterol Nutr 2006;42:392-397.

26. Okada T, Sasaki F, Asaka M, Kato M, Nakagawa M, Todo S. Delay of gastric emptying measured by ${ }^{13} \mathrm{C}$-acetate breath test in neurologically impaired children with gastroesophageal reflux. Eur J Pediatr Surg
2005;15:77-81.

27. Zangen T, Ciarla C, Zangen S, et al. Gastrointestinal motility and sensory abnormalities may contribute to food refusal in medically fragile toddlers. J Pediatr Gastroenterol Nutr 2003;37:287-293.

28. Pauwels A, Altan E, Tack J. The gastric accommodation response to meal intake determines the occurrence of transient lower esophageeal sphincter relaxations and reflux events in patients with gastro-esophageal reflux disease. Neurogastroenterol Motil 2014;26:581-588.

29. Fukahori S, Asagiri K, Ishii S, et al. Pre and post-operative evaluation of gastroesophageal reflux and esophageal motility in neurologically impaired children using combined $\mathrm{pH}$-multichannel intraluminal impedance measurements. Pediatr Surg Int 2013;29:545-551.

30. Emerenziani S, Sifrim D. Gastroesophageal reflux and gastric emptying, revisited. Curr Gastroenterol Rep 2005;7:190-195.

31. Schwizer W, Hinder RA, DeMeester TR. Does delayed gastric emptying contribute to gastroesophageal reflux disease? Am J Surg 1989;157:74-81.

32. Tjon JA, Pe M, Soscia J, Mahant S. Efficacy and safety of proton pump inhibitors in the management of pediatric gastroesophageal reflux disease. Pharmacotherapy 2013;33:956-971.

33. Borrelli O, Battaglia M, Galos F, et al. Non-acid gastro-oesophageal reflux in children with suspected pulmonary aspiration. Dig Liver Dis 2010;42:115-121. 